\title{
PERCEPTION AND KNOWLEDGE ON FACTORS AFFECTING PATIENT SAFETY AMONG NURSES
}

\author{
Dr. Lizy Sonia Benjamin* \& Dr. Kiruba J. C** \\ *Assistant Professor, Nursing College, Abha, King Khalid University, Saudi Arabia. \\ **Professor, SSNMM College of Nursing, Varkala, India. \\ DOI: http://doi.org/10.47211/idcij.2020.v07i03.017 \\ Received $28^{\text {th }}$ May 2020, Accepted $20^{\text {th }}$ June 2020, Available online $10^{\text {th }}$ July 2020.
}

ABSTRACT

The necessity for quality and safety improvement initiatives permeates health care. Patient safety is one of the major goals adapted national wide especially by World Health Organization (WHO). According to national guidelines, patient safety skills should be part of everyday nursing work. The nurses must have knowledge and skills to prevent any possible harm to patients. Objective: To assess the perceptions and knowledge on patient safety among nurse's students. Method: The study uses descriptive cross-sectional design to study among 105 nurses selected through purposive sampling technique at selected hospital, Kerala. The data was collected using patient safety tool developed by Texas-Memorial Hermann Centre for Healthcare Quality and Safety and demographic questionnaire. The data were analysed using the statistical software SPSS 22 version. Results: The results of the study showed the age of most nurses were between 21 and 29 years (78.6\%). Most participants had 1-5 years of experience in nursing (60.3\%). Only $34.2 \%$ of participants attended at least one course in safety during their experience. There were positive scores (76.8) of nurses perception towards patient safety, and positive scores of four subscales out of six. ANOVA test revealed significant relations between patient safety and nurses' age, experience, degree, and previous attendance of safety courses. On the other hand, analysis of gender, working area, and role of nurses showed no significant differences. Nurses with experience more than 10 years had the most positive responses $(F=2.75, p<0.05)$. In addition, nurses holding bachelor certificate had more positive scores than those with diploma certificate ( $F=4.36, p<0.05)$. Nurses who attended safety courses had more positive responses than those did not attend. On the other hand, analysis of gender, working area, and role of nurses showed no significant differences. Conclusion: The findings of the study will help nurse managers to create awareness of the nurses regarding patient safety should be raised and their related knowledge should be kept up-to-date through more frequent in-service trainings.

Keywords: Patient safety, nurses' perception, quality of care.

\section{ABOUT AUTHORS:}

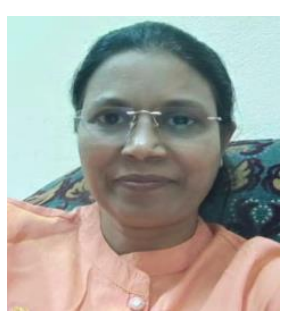

Author Dr. Lizy Sonia Benjamin is Assistant Professor at Nursing College, Abha, King Khalid University, Saudi Arabia.

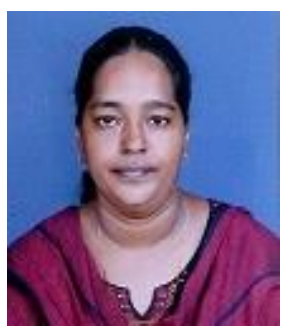

Author Dr. Kiruba J. C is working as Professor, SSNMM College of Nursing, Varkala, India. 


\section{INTRODUCTION}

Prevention of healthcare-related errors and reduction or elimination of patient problems caused by such errors is based on formation of the patient safety culture. Therefore, patient safety culture is important in terms of representation of quality healthcare services. The patient safety involves all measures and precautions made for reduction or elimination of possible adverse effects of medical care during medical diagnosis and treatment.

Patient safety refers to the reduction of risk of unnecessary harm associated with healthcare to an acceptable minimum. An acceptable minimum means the collective notions of given current knowledge, resources available and the context in which care was delivered weighed against the risk of non-treatment or other treatment (WHO, 2014). Patient safety is the reduction and mitigation of unsafe acts within the healthcare system, as well as using best practices shown to lead to optimal patient outcomes (Canadian Patient safety Institute, 2012).

Patient safety is inseparable from the quality of nursing education. Existing research shows that the introduction of patient safety should be part of the education at all levels of the healthcare system (Noviyanti, 2018). One study stated that the quality of education delivered to nursing students can significantly reduce medical errors and improve the safety culture and quality of service.

Nurses working at intensive care units have a crucial role in the establishment of a safe and qualified care for the patients. Nurses give constant care, apply complicated medications, use various technological equipment and offer care to patients in need of advanced life support.

It is required to determine primarily the patient safety culture in the institution in order to enhance the patient safety culture and prevent deficiencies, practices or risk factors causing medical errors. The purpose of this study was to assess tools used for patient safety and their related knowledge.

\section{OBJECTIVES}

- To assess the knowledge on assessment methods of patient safety among nurses.

\section{MATERIALS \& METHODS}

A descriptive cross-sectional design was adopted for this study. The study population consisted of 105 nurses working at selected tertiary care hospital, Kollam, Kerala were recruited through non-probability purposive sampling technique. The questionnaire, designed by the researchers upon a comprehensive survey of literature, involved socio-demographic characteristics of the nurses and included questions about patient safety.

Data were collected using a self-administered questionnaire. Participants were asked 20 knowledge-based questions. They had to give a self-evaluation of their knowledge of patient safety. A questionnaire of fours parts was prepared as follows: the first part aimed to collect the demographic information of the nurses (gender, age, hospital ward); the second part was questionnaire related to the types of assessment tools used for patient safety which has 20 items. The reliability of the questionnaire was determined using test-retest method $(r=0.85)$. In order to comply with ethical considerations, the researchers explained the aim of the study to the study participants and then they were assured that the information will be confidential. Data analysis was done using statistical software package SPSS for windows version 22. Appropriate descriptive and inferential statistics were used to analyse the data.

\section{RESULTS}

A total of 110 nurses were invited to participate in study; however, only 105 nursing students completed and returned the questionnaires (response rate 95.45\%) and 5 nurses were excluded due to incomplete filling of questionnaires.

In the present study a total of 105 nurses were enrolled. Majority of the nurses were in the age group of 21 to 29 years $(78.6 \%)$, qualified with B.Sc. nursing $(59.4 \%)$, majority of the females $(76 \%)$ and they had total experiences between 1 to 5 years $(60.3 \%)$ in ward. Only $65.8 \%$ of participants attended at least one course in safety during their experience as shown in Table 1.

Table 2 infers the dimensions of patient safety. Majority of participants $88.3 \%$ had mean score of $(M=82.4)$ related to teamwork climate, $75.8 \%$ had mean score $(\mathrm{M}=74.9 \%)$ related to safety climate, $64.8 \%$ had mean score of $(M=63)$ related to perception of management, $86.6 \%$ had mean score of $(M=84.2)$ related to job satisfaction, $83.7 \%$ had mean score of $(M=73.7)$ related to working conditions and $61.8 \%$ had mean score of $(M=58.3)$ related to stress recognition.

Table 3 refers to nurses with experience more than 10 years had the most positive responses $(F=2.75, p<$ 0.05). In addition, nurses holding bachelor certificate had more positive scores than those with diploma 


\section{ARTICLES}

certificate $(F=4.36, p<0.05)$. Nurses who attended safety courses had more positive responses than those did not attend. On the other hand, analysis of gender, working area, and role of nurses showed no significant differences.

Table 1. Frequency and Percentage distribution of Demographic characteristics of participating nurses $(\mathrm{N}=105)$

\begin{tabular}{|l|l|c|c|}
\hline Variable & Groups & Frequency & (\%) \\
\hline \multirow{4}{*}{ Sex } & Male & 20 & 24 \\
\cline { 2 - 4 } & Female & 80 & 76 \\
\hline \multirow{5}{*}{ Education } & $21-29$ & 83 & 78.6 \\
\cline { 2 - 4 } & $30-39$ & 15 & 19.7 \\
\cline { 2 - 4 } & $40-49$ & 2 & 1.7 \\
\hline \multirow{5}{*}{ Experience } & Diploma & 43 & 40.6 \\
\cline { 2 - 4 } & B.Sc.(N) & 62 & 59.4 \\
\hline \multirow{5}{*}{ Working area } & Less than 1 year & 8 & 7.7 \\
\cline { 2 - 4 } & $1-5$ years & 63 & 60.3 \\
\cline { 2 - 4 } & 6-10 years & 32 & 30.3 \\
\cline { 2 - 4 } & More than 10 years & 2 & 1.7 \\
\hline \multirow{5}{*}{ Role } & Critical care unit & 10 & 9.4 \\
\cline { 2 - 4 } & Medical ward & 35 & 33.3 \\
\cline { 2 - 4 } & Surgical ward & 39 & 36.8 \\
\cline { 2 - 4 } & Emergency unit & 8 & 8.1 \\
\cline { 2 - 4 } & Operation room & 13 & 12.4 \\
\hline \multirow{5}{*}{ Attending Safety Course } & Care giver & 91 & 86.8 \\
\cline { 2 - 4 } & Educator & 2 & 2.1 \\
\cline { 2 - 4 } & Administrative & 64 & 11.1 \\
\cline { 2 - 4 } & Yes & 36.2 \\
\cline { 2 - 4 } & No & & 65.8 \\
\hline
\end{tabular}

Table 2. The relationships between characteristic of participants and dimensions of patient safety

\begin{tabular}{|l|c|c|}
\hline Safety Questionnaire Items & \% & Mean \\
\hline Teamwork climate & 88.3 & 82.4 \\
\hline Safety climate & 75.8 & 74.9 \\
\hline Perception of management & 64.8 & 63 \\
\hline Job satisfaction & 86.6 & 84.2 \\
\hline Working Conditions & 83.7 & 73.7 \\
\hline Stress recognition & 61.8 & 58.3 \\
\hline
\end{tabular}


Table 3. The relationship between nurse participants' demographic characteristics and their perceptions toward patient safety issues ( $N=105)$

\begin{tabular}{|c|c|c|c|c|}
\hline Variable & Groups & Score & $\mathbf{F}$ & $p$ value \\
\hline \multirow[t]{2}{*}{ Sex } & Male & 74.3 & \multirow[t]{2}{*}{3.86} & \multirow[t]{2}{*}{0.06} \\
\hline & Female & 77.2 & & \\
\hline \multirow[t]{3}{*}{ Age in years } & $21-29$ & 58.1 & \multirow[t]{3}{*}{3.21} & \multirow[t]{3}{*}{$0.04 *$} \\
\hline & $30-39$ & 66.8 & & \\
\hline & $40-49$ & 78.3 & & \\
\hline \multirow[t]{2}{*}{ Education } & Diploma & 75.2 & \multirow[t]{2}{*}{4.36} & \multirow[t]{2}{*}{$0.01 * *$} \\
\hline & B.Sc. (N) & 83.2 & & \\
\hline \multirow[t]{4}{*}{ Experience } & Less than 1 year & 68.4 & \multirow[t]{4}{*}{2.75} & \multirow[t]{4}{*}{$0.00 * * *$} \\
\hline & $1-5$ years & 72.9 & & \\
\hline & $6-10$ years & 76.5 & & \\
\hline & More than 10 years & 87.3 & & \\
\hline \multirow[t]{5}{*}{ Working area } & Critical care unit & 85.7 & \multirow[t]{5}{*}{2.72} & \multirow[t]{5}{*}{$0.03^{*}$} \\
\hline & Medical ward & 76.8 & & \\
\hline & Surgical ward & 77.3 & & \\
\hline & Emergency unit & 69.3 & & \\
\hline & Operation room & 67.4 & & \\
\hline \multirow[t]{3}{*}{ Role } & Care giver & 76.8 & \multirow[t]{3}{*}{3.57} & \multirow[t]{3}{*}{0.06} \\
\hline & Educator & 82.1 & & \\
\hline & Administrative & 79.9 & & \\
\hline \multirow{2}{*}{$\begin{array}{l}\text { Attending } \\
\text { Safety Course }\end{array}$} & Yes & 86.7 & \multirow[t]{2}{*}{2.89} & \multirow[t]{2}{*}{$0.02 *$} \\
\hline & No & 73.6 & & \\
\hline
\end{tabular}

\section{DISCUSSION}

The current study was conducted to find out the nurse's perception and knowledge about factors affecting patient safety. The total score of nurse's perception was positive (72.8). The mean score is consistent with the score of some previous studies conducted by (Şahin et al., 2015).

Several nursing characteristics were examined to assess their relations with perception of patient safety. The results revealed significant relations between age, experience, education, working area, attending previous courses and nurse's perception of patient safety. The findings were congruent with another study (Holden et al., 2009; Bahir and Herdman, 2008). In this study there was no significant relation between sex as well as nurses role as a care giver and their perception of patient safety. Similarly, some studies get the same result (Abdolahzadeh et al., 2012).

The study highlighted the highest positive scores was among the most experienced nurses more than 10 years while the lowest positive score was among diploma nurses. The high positive scores also found in nurses holding B.Sc. (N) working in critical care unit and who previously attended courses in patient safety. The results can be compared with similar findings highlighted by Singer et al. (2009). The results were significant for working area related to patient safety.

\section{CONCLUSION}

This study showed the various assessment tools used to measure patient safety among nurses. The findings of the study will help nurse managers to create awareness of the nurses regarding patient safety should be raised and their related knowledge should be kept up-to-date through more frequent in-service trainings. 


\section{REFERENCES}

1. Abdolahzadeh, F., Zamanzadeh1, V., Boroumand, A. (2012). Studying the Relationship between Individual and Organizational Factors and Nurses' Perception of Patient Safety Culture. Journal of Caring Sciences, 2012, 1(4), 215-222

2. Abdou, H. \& Saber, K. (2011). A baseline assessment of patient safety culture among nurses at Student University Hospital. World Journal of Medical Sciences, 6, 17-26.

3. Aspden, P., Corrigan, J., Wolcott, et al., (2005). Patient safety: achieving a new standard for care. Washington, DC: National Academies Press.

4. Hayajneh, Y.A., Abualrub, R.F. \& Almakhzoomy, I.K. (2010). Adverse events in Jordanian hospitals: types and causes. International Journal of Nursing Practice, 16, 374-380.

5. Holden, L., Watts, D., \& Walker, P. (2009). Patient safety climate in primary care: age matters. Journal of Patient Safety, 5(1): 23-8.

6. Khater, W., Akhu-Zaheya, L., AL-Mahasneh, S. \& Khater, R. (2015) Nurses" perceptions of patient safety culture in Jordanian hospitals. International Nursing Review. 62, 82-91

7. Noviyanti, L.W., Handiyani, H. \& Gayatri, D. Improving the implementation of patient safety by nursing students using nursing instructors trained in the use of quality circles. BMC Nurs 17, 53 (2018). https://doi.org/10.1186/s12912-018-0318-7

8. WHO. (2014). Patient Safety. WHO Regional Office for Europe.

9. Canadian Patient safety institute. (2012). What is quality and patient safety? www. Patient safety institute. 